\title{
Artikel
}

\section{Het verdrag en het veld}

\author{
Over mensenrechten, dwang en drang
}

Prof. dr. P. Ippel en dr. G. Blok*

\section{Inleiding}

Iedereen weet dat een nieuwe wet kan 'afstuiten' op de sociale werkelijkheid, dat het goedbedoelde voorschrift in een juridische regel niet strookt met de soms barse realiteit. Vooral rechtssociologen en politicologen hebben zich beziggehouden met de vraag of en hoe law in the books al dan niet uitloopt op law in action: slechts onder heel bepaalde voorwaarden zal een formeel afgekondigde regel een hoge effectiviteit hebben. Dat geldt misschien in nog sterkere mate voor ideële, maar altijd abstracte beginselen en normen, zoals die in constitutionele teksten (Grondwet) of internationale mensenrechtenverdragen zijn verwoord. De bekende Amerikaanse sociologe Sally Engle Merry heeft in diverse publicaties geprobeerd meer greep te krijgen op de bepalende factoren in het vertaalproces van wereldwijd verdrag naar het 'lokale' veld. ${ }^{1}$ In ieder geval blijkt een officiële strategie-van-bovenaf nooit krachtig genoeg, er is ook altijd actie-van-onderop geboden.

In dit korte artikel gaan we in op de vraag op welke wijze het onlangs door het Nederlandse parlement bekrachtigde VN-Verdrag over 'de rechten van mensen met een beperking' door zal kunnen werken in de brede sector

* Prof. dr. Pieter Ippel is hoogleraar rechtsgeleerdheid aan het University College Roosevelt te Middelburg en de Universiteit Utrecht. In 2016 is hij ook research fellow bij Tilburg University Law School. Dr. Gerco Blok is psychiater en geneesheer-directeur van Emergis, het centrum voor geestelijke gezondheidszorg in Zeeland.

1. Zie met name: Sally Engle Merry, Human Rights \& Gender Violence. Translating International Law into Local Justice, Chicago and London: The University of Chicago Press 2006 van de geestelijke gezondheidszorg. Het nieuwe VNVerdrag - de UN-Convention on the Rights of Persons with Disabilities - (IVRPH) formuleert niet zozeer een serie nieuwe rechten, maar zet de voor mensen met beperkingen meest relevante aanspraken systematisch bij elkaar. Zo wordt nog eens - symbolisch - onderstreept dat de erkenning en verwerkelijking van deze rechten serieus moeten worden genomen.

Voor zover wij hebben kunnen nagaan is er in de wereld van de geestelijke gezondheidszorg nog niet of nauwelijks nagedacht over de relevantie van het nieuwe verdrag voor de positie van patiënten en cliënten. ${ }^{2}$ De kernboodschap van het verdrag is dat mensen met een beperking zo volledig mogelijk toegang moeten kunnen krijgen tot maatschappelijke voorzieningen, bijvoorbeeld in de sfeer van wonen, werk en zorg. Dat essentiële mensenrechtelijke signaal kan met name voor langdurige of 'chronische' gebruikers van de geestelijke gezondheidszorg een steun in de rug zijn. Hun 'handicap' is vaak nauwelijks zichtbaar, maar die beperking kan hen ernstig hinderen in het streven naar een acceptabele kwaliteit van het bestaan.

In dit artikel gaan wij vooral in op de mogelijke implicaties van het verdrag voor het vraagstuk van dwang bij opname, behandeling en bejegening. Alleen als we goed de kenmerken en achtergrond van recente en actuele ontwikkelingen in het vizier krijgen, wordt het mogelijk een schatting te geven van de perspectieven (en beperkingen) van de 'implementatie' van het verdrag in het

2. In de zorg voor personen met (fysieke of verstandelijke) handicap lijkt het belang van (doorwerking van) dit VN-Verdrag nu te worden ontdekt. Zie bijvoorbeeld: Femke Halsema, 'Plaats individu centraal in zorg', de Volkskrant 7 september 2016, waarin onder meer de zin staat: 'Alle mensen met een beperking verdienen een afdwingbaar recht op zorg.' 
veld, van de overgang van rechten op papier naar handelen op de werkvloer.

Daarbij is allereerst van belang stil te staan bij de ontwikkelingen binnen de geestelijke gezondheidszorg in de laatste decennia. 'Vermaatschappelijking', 'zorg op maat' en een 'persoonsgerichte behandeling' zijn de laatste jaren karakteristieke en centrale beleidsdoelstellingen. Dat klinkt veelbelovend, omdat ook het VN-Verdrag zich richt op een zo volledig mogelijke deelname van personen met een handicap aan het maatschappelijke leven. Maar er is ook tegenwind: de ggz staat onder financiële en organisatorische druk. Terwijl het verdrag zich richt op 'inclusie', op participatie van de patiëntals-burger is het politiek-culturele klimaat af en toe rauw en juist gericht op opsluiting en 'onschadelijkmaking'. Het veld blijkt geen idyllisch park, het is een strijdperk.

Hierbij is het - in de tweede plaats - noodzakelijk te beseffen dat het niet de eerste keer is dat psychiatrie en mensenrechten elkaar 'ontmoeten'. Vanaf de jaren zeventig is de (verbetering van de) rechtspositie van de psychiatrische patiënt een toonaangevend thema in de rechtspolitieke discussie over de geestelijke gezondheidszorg. Al in 1979 deed het Europese Hof voor de Rechten van de Mens uitspraak in een door een Nederlandse patiënt (Winterwerp) aangespannen procedure en dat gaf een impuls aan de vernieuwing van de wetgeving. ${ }^{3}$ De Wet Bopz was de opvolger van de verouderde Krankzinnigenwet van 1884 en richtte zich meer op verwerkelijking van grondrechten, met name voor en rond de dwangopname. ${ }^{4}$ Ook in het nieuwe wetsvoorstel over Verplichte geestelijke gezondheidszorg is versteviging van de rechtspositie van de ggz-gebruiker een drijfveer. Tegelijkertijd introduceert dit wetsontwerp nieuwe faciliteiten voor ambulante, moeilijker te controleren dwang en er bestaat vrees dat het netto-effect vanuit patiëntenperspectief ongunstig zal zijn.

Het is - zoals gezegd - onmogelijk om over de volle breedte de mogelijke consequenties van het VN-Verdrag voor de (ingewikkelde) ggz te inventariseren. Wij proberen met name iets te zeggen over een klassiek dilemma in de (intramurale) psychiatrie, namelijk: in hoeverre mogen we dwang toepassen om het welzijn van de patiënt of van direct betrokken anderen te dienen? Onze stelling zal zijn dat de aspiraties van het VN-Verdrag vooral concrete betekenis kunnen krijgen wanneer wordt aangesloten bij al eerder op gang gekomen, breed gedragen bewegingen. De rechtsfilosoof en praktijkjurist Lon Fuller stelde al een halve eeuw geleden dat het

3. Zie hierover al ruim 35 jaar terug: Arthur Frid, Pieter Ippel en Paul Laurs, Jij liever dan ik. De psychiatrische patient: wat heeft hij te vertellen?, Den Haag: VUGA 1980.

4. Zie over de recente praktijk van de dwangopnameprocedure: Pieter Ippel, De binnenkant. De praktijk van recht en ethiek in de psychiatrie, Den Haag: Boom/Lemma 2012, met name hoofdstuk 4 'Dwang blijft wrang'. Na de inwerkingtreding van de Wet Bopz in 1994 is de regeling diverse keren gewijzigd. Zo zijn de mogelijkheden voor (medicamenteuze) dwangbehandeling, die mede in het licht van het grondrecht op lichamelijke integriteit in art. $11 \mathrm{Gw}$ lang werden afgewezen, in principe verruimd. Vaker dan voorheen wordt dwangbehandeling toegepast en het is niet duidelijk of het rechterlijk toezicht daarop goed functioneert. recht niet alleen kan worden begrepen als een systeem van regels, rechten en plichten, maar dat er in de rechtsontwikkeling altijd de prikkel van een morality of aspiration moet zijn. ${ }^{5}$ Wij denken dat de drijfveren achter en de kernboodschap van het VN-Verdrag een morality of inspiration kunnen zijn voor zowel patiënten als gezondheidswerkers.

\section{Tendensen in de geestelijke gezondheidszorg}

Er is de afgelopen jaren een brede beweging ingezet om dwang en drang binnen de psychiatrie te verminderen, waarbij vooral het verblijf van patiënten in een isoleercel (ook wel separatie genoemd) uitgebreid aandacht heeft gekregen. In juni 2015 constateerde de Inspectie Gezondheidszorg (IGZ) dat er sinds 2006 daadwerkelijk flinke stappen zijn gezet in het terugdringen van het aantal en de duur van de separaties. De IGZ voegt daar wel meteen krachtig aan toe dat er geen aanleiding is om achterover te leunen: er zijn 'verdere acties' nodig om de eerder geformuleerde ambities te halen. ${ }^{6}$ Een hiermee samenhangende, veelbelovende ontwikkeling is die van gespecialiseerde afdelingen voor acute psychiatrie, waarbij behoud van menselijk contact en individuele begeleiding centraal komen te staan. In de vormgeving van de gebouwen en afdelingen en in de samenstelling van het behandelteam wordt hier uitdrukkelijk aandacht aan besteed. Deze afdelingen - 'High en Intensive Care'afdelingen - vormen ook in toenemende mate het uitgangspunt in de vormgeving van de klinische behandeling van acuut opgenomen psychiatrische patiënten.

Mede onder invloed van de landelijke patiëntenorganisatie LPGGZ en ook door de inbreng van ervaringswerkers is de herstelgerichte behandeling in veel ggz-instellingen voorop komen te staan. In veel gevallen is een volledige 'genezing' van een psychische stoornis niet mogelijk, maar passende ondersteuning op verschillende levensgebieden via ambulante behandeling kan de perspectieven op een 'gewoon' (goed) leven voor langdurig op zorg aangewezen personen verruimen. In dit raamwerk is ook de toenemende wijkgerichte benadering en versterking van het ambulante karakter van de psychiatrie te zien. Veel psychiatrische patiënten, die vroeger op het inrichtingsterrein verbleven, wonen nu midden in de maatschappij, met name in 'beschermde woonvormen'.

Deze beide tendensen - het zoeken naar alternatieven voor dwang en drang en de 'vermaatschappelijking' van de ggz - kunnen worden gezien als de erkenning van de

5. Zie het klassieke boek van Lon L. Fuller, The Morality of Law, New Haven and London: Yale university Press 1969 (1964). Fullers werk was een inspiratiebron voor het belangrijke recente boek van Willem Witteveen, De wet als kunstwerk. Een andere filosofie van het recht, Amsterdam: Boom 2014

6. Inspectie voor de Gezondheidszorg, GGZ-instellingen investeren in terugdringen van separatie; verdere acties nodig om ambities te halen, Utrecht, juni 2015. 
menselijke waardigheid en de aanspraak op maatschappelijke participatie van (vaak moeilijk levende) mensen. $\mathrm{Zij}$ liggen in het verlengde van wat het VN-Verdrag nastreeft. Artikel 12 IVRPH stelt dat 'personen met een handicap overal als persoon erkend worden voor de wet'. Uit het vervolg van deze bepaling blijkt dat dit inhoudt dat individuen niet te gemakkelijk of onzorgvuldig als wilsonbekwaam mogen worden bejegend. ${ }^{7}$ Ook wanneer sprake is van verminderde wilsbekwaamheid, dienen de wensen en belangen van de betrokkene zo goed mogelijk te worden verdisconteerd en waar mogelijk moet in de richting van herstel van autonomie worden gekoerst. Ook artikel 14 IVRPH moet worden genoemd, dat nog eens onderstreept dat vrijheidsbeneming 'niet onrechtmatig of willekeurig' mag gebeuren. Dwang bij opname en tijdens het verblijf dient daadwerkelijk een 'uiterste remedie' te zijn en 'op de werkvloer' moet men voortdurend blijven zoeken naar humane, persoonsgerichte zorg, die vrijheidsbeperking kan vermijden.

Helaas is er ook een andere (achter)kant van het verhaal. Ondanks het streven naar vermindering van dwang en drang tijdens het verblijf, laat onderzoek zien dat er in Nederland een gestage toename van het aantal dwanginterventies in het kader van de Wet Bopz (de Wet bijzondere opnemingen in psychiatrische ziekenhuizen) is opgetreden: in 2002 waren er ruim 12.500 dwangopnames (de spoedopname In Bewaring Stelling en de langdurige Rechterlijke Machtiging) en in 2015 ging het om bijna 24.500 gevallen, bijna een verdubbeling dus. ${ }^{8}$

Het is niet eenvoudig hiervoor een omvattende verklaring te geven. Mogelijk heeft deze opmerkelijke stijging te maken met het wegvallen van (preventieve en laagdrempelige) maatschappelijke voorzieningen en met de introductie van een eigen bijdrage in de zorg, waardoor een groep ernstige patiënten de (vrijwillige) zorg gaat mijden. Een afgenomen maatschappelijke tolerantie ten aanzien van afwijkend, verward, overlastgevend gedrag speelt zeker ook een rol. Er is ontegenzeglijk een toegenomen maatschappelijke druk vanuit gemeenten, politie en andere maatschappelijke organisaties om eerder in te grijpen en mensen (desnoods gedwongen) op te nemen om op die manier maatschappelijke overlast terug te dringen. Schokkende incidenten - zoals de moord op oud-minister Els Borst door een gestoorde man - geven voeding aan de wens om dwangmaatregelen juist te verruimen. ${ }^{9}$

7. Wanneer wel sprake is van wilsonbekwaamheid is adequate vertegenwoordiging noodzakelijk.

8. Zie nieuwsbericht 'Aantal dwangopnamen bijna verdubbeld', Nieuwsuur 29 augustus 2016, gebaseerd op cijfers van de Raad voor de Rechtspraak. Zie voor de precieze aantallen en een beschouwing: J. Broer, $\mathrm{H}$. Koetsier \& C.L. Mulder, 'Stijgende trend in dwangtoepassing onder de Wet Bopz zet door. Implicaties voor de nieuwe Wet verplichte geestelijke gezondheidszorg', Tijdschrift voor psychiatrie 57 (2015)4, p. 240-247. De stijging doet zich vooral voor bij (voorwaardelijke) rechterlijke machtigingen.

9. In het in de zomer van 2016 bekend geworden gewijzigde wetsvoorstel 'Wet verplichte geestelijke gezondheidszorg' (Kamerstukken II 32399, 2 ) is in art. 7A een nieuwe vorm van dwanginterventie - de observatiemachtiging - voorzien. Die wijziging lijkt een reactie op de maatschappelijke onrust door de moord op mevrouw Borst en andere soortgelijke incidenten.
Er lijkt in het algemeen een maatschappelijke tendens merkbaar, die ertoe leidt dat mensen met beperkingen die voortkomen uit psychiatrische problematiek minder gemakkelijk toegang hebben tot basale levensvoorwaarden, zoals zelfstandige huisvesting of een (aangepaste) baan. Als gevolg van bezuinigingen staat het aantal beschermde woonvormen onder druk. Veel cliënten en hulpverleners ervaren dat sociale verhuurders als woningbouwverenigingen toenemend drempels opwerpen om mensen met een psychiatrische aandoening een huurwoning te doen toekomen. Het is duidelijk dat dit op gespannen voet staat met letter en geest van het $\mathrm{VN}$ Verdrag dat in artikel 19 uitdrukkelijk het recht op zelfstandig wonen en het zo 'het deel uitmaken van de maatschappij' onderstreept.

Ook een ander aspect verdient vermelding. Heel uiteenlopende bestuurlijke en maatschappelijke organisaties oefenen druk uit om (persoonsgerelateerde) informatie te ontvangen over de psychische gezondheid van mensen die zorg krijgen binnen of buiten psychiatrische instellingen. Het argument is vaak dat 'vroegsignalering' of 'preventie' met het vergaren van deze persoonsgegevens gediend is, maar de risico's op misbruik en stigmatisering zijn evident. Dit leidt met regelmaat tot situaties waarbij het beroepsgeheim van de zorgprofessionals en de eerbiediging van de privacy (zie artikel 22 IVRPH) onder druk komen te staan.

Deze beide kort aangestipte maatschappelijke bewegingen - de een gericht op inclusie, de andere eerder op uitsluiting - kunnen diametraal tegenover elkaar komen te staan. Het al eerder genoemde wetsvoorstel betreffende de Wet verplichte geestelijke gezondheidszorg (Wvggz) laat deze tegengestelde opvattingen ook goed zien. Aan de ene kant stelt het wetsvoorstel uitdrukkelijk voorop dat gedwongen psychiatrische opname en behandeling alleen als ultimum remedium mag worden ingezet en is er expliciet aandacht voor vertegenwoordiging wanneer een individu als wilsonbekwaam mag worden beschouwd. Ook wordt aangegeven dat zelfs bij de aanvraag van een verplicht behandeltraject de betrokkene zelf (al dan niet samen met familie) met een zogeheten 'zorgplan' kan komen om op die manier verplichte zorg te voorkomen. De autonomie van de mens of het herstel daarvan staat hierbij centraal. Anderzijds is er - zoals we al zagen - op het laatste moment een observatiemaatregel in het wetsvoorstel opgenomen, waarbij iemand bij wie een vermoeden is van een psychiatrische stoornis en bij wie mogelijk gevaar dreigt, relatief gemakkelijk gedurende een aantal dagen in een gesloten klinische omgeving geobserveerd kan worden. ${ }^{10}$ Overigens is er op dit laatste voorstel veel kritiek, zowel vanuit de branche- en beroepsorganisaties als vanuit de LPGGZ.

10. Hoewel voor deze dwanginnovatie in het parlement wel steun lijkt te bestaan, is er breed gedragen kritiek vanuit de branche- en beroepsorganisaties en vanuit de patiëntenbeweging. Op internet is een voorstel voor een petitie te vinden met als karakteristieke slogan: 'Wetgevers: regel zorg in plaats van dwang'. 


\section{Mensenrechten en ethiek in de zorg}

Het VN-Verdrag poneert in essentie geen nieuwe (mensen)rechten, maar accentueert, articuleert en activeert een aantal in andere verdragen opgenomen bepalingen. Wanneer we het hebben over de problematiek van dwang en drang zijn de clausules over het recht op vrijheid (artikel 14), vrijwaring van een wrede behandeling (artikel 15) en bescherming van de persoonlijke integriteit (artikel 17) relevant. Daarbij gaat het om de klassieke burgerlijke en politieke vrijheden, die bijvoorbeeld ook in het Europees Verdrag voor de Rechten van de Mens zijn vastgelegd. Tegelijkertijd wordt in het verdrag ook gesproken over het recht op gezondheid (artikel 25) en op (re)habilitatie en revalidatie (artikel 26). Daarbij gaat het om de zogenoemde tweede generatie grondrechten, de sociaal-economische mensenrechten. Voor de enorm grote groep van personen met een beperking is het recht op goede, toegankelijke zorg van existentieel belang.

Hier is de volgende observatie van belang. Veel van wat in dit mensenrechtendiscours wordt geformuleerd sluit aan bij centrale waarden in de gezondheidsethiek en de beroepsethiek van artsen, verpleegkundigen en verzorgenden. In hun wereldwijd bekend geworden handboek over bio-ethiek formuleren Beauchamp en Childress vier richtinggevende principes, namelijk respect voor 'autonomie', 'weldoen', 'niet schaden' en het streven naar 'rechtvaardige verdeling'. Het komt erop aan in de praktijk te zoeken naar een beredeneerd en werkzaam evenwicht. Soms is (paternalistisch) 'weldoen' te prefereren boven niets doen, zeker wanneer de betrokkene door zijn stoornis niet goed kan inschatten wat in zijn belang is en zijn wil niet adequaat kan bepalen. Maar ook in dat geval gaat het om het bevorderen van het welzijn en het herstel van de zelfbeschikking van de patiënt. Alleen wanneer er een gezonde onderlinge 'aanspreekcultuur' is en wanneer gezondheidswerkers bereid zijn hun keuzes te verantwoorden, kan misbruik van macht worden voorkomen. Dit komt ook naar voren uit het proefschrift van ethicus en psychiatrisch verpleegkundige Yolande Voskes uit 2015, waarin zij op grond van veldonderzoek concludeert dat duurzame effectiviteit in het terugdringen van dwang- en dranginterventies alleen bereikt kan worden wanneer er een stevige morele infrastructuur op de werkvloer is gegroeid: 'no effect without ethics' ${ }^{11}$

\section{Het verdrag in het veld}

Door de ratificatie van het 'Internationale Verdrag inzake de Rechten van Personen met een Handicap' is dit

11. Yolande Voskes, No effect without ethics. Reduction of seclusion in psychiatry from a care ethics perspective, dissertatie VU, Amsterdam 2015. internationale juridische document formeel tot ons eigen Nederlandse recht gaan behoren. Willen de in dit verdrag verwoorde (vaak aspiratieve) normen ook daadwerkelijk tot het levende recht gaan horen, dan is er meer nodig.

Globaal valt er aan drie 'implementatiemodellen' te denken. Het eerste is het politiek-maatschappelijke strijdstramien. In het parlement (politieke partijen) en daarbuiten (denk aan gehandicaptenorganisaties) proberen mensen krachtig gehoor te vinden voor hun eis dat de woorden in daden worden omgezet. Het is namelijk naief om te verwachten dat de regering en andere overheidsinstanties de rechten van mensen met een beperking in de beleidspraktijk altijd prioriteit zullen geven. De tweede benadering zou een activistisch-juridische aanpak kunnen zijn: de in het verdrag neergelegde rechten worden voor de nationale of internationale rechter rechtens afgedwongen. Lang is aangenomen dat de realisering van sociaal-economische mensenrechten niet door rechterlijke instanties zou kunnen worden afgedwongen - de rechten zouden niet justiciable zijn - maar de laatste decennia is dit in uiteenlopende landen en in diverse rechterlijke fora wel met succes bekroond. ${ }^{12}$

Wij denken zeker dat deze twee genoemde strategieën noodzakelijk (kunnen) zijn. Maar wij bepleiten zeker ook een derde route: de moreel-praktische benaderingvan-onderop. Het gaat niet alleen om de empomerment van personen met een beperking, maar tegelijkertijd om mobilisering van het morele en praktische potentieel bij de hulpverleners: artsen, psychologen, maar vooral ook de veel grotere groep verpleegkundigen, groepsleiders en verzorgenden. $\mathrm{Zij}$ zullen in de praktijk van alledag het verschil kunnen maken.

Wij hebben niet de pretentie of de illusie dat het in dit artikel besproken probleem van dwang en drang in de psychiatrie binnenkort 'opgelost' of drastisch 'gereduceerd' kan worden. Het gaat om een taai thema, om een weerbarstige kwestie, in de woorden van psychiatriehistoricus Vijselaar: om een 'historisch dilemma' ${ }^{13}$ Maar wel kan het verdrag initiëren, inspireren en instigeren tot minder dwang en betere (toegang) tot zorg. Wij eindigen met enkele concrete suggesties.

In de eerste plaats lijkt een intensief en inspirerend voorlichtings- en mobiliseringstraject over dit VN-Verdrag dichtbij de werkvloer noodzakelijk. Het gaat daarbij zeker om empomerment van patiënten, die goed past in herstelgerichte benadering in de geestelijke gezondheidszorg. Het zal ook moeten gaan om het activeren van verpleegkundigen, artsen, psychologen en andere praktijkwerkers. Wanneer alleen de betrekkelijk kleine

12. Zie hierover: Fons Coomans (red.), Justiciability of Economic and Social Rights. Experiences from Domestic Systems, Antwerpen/Oxford: Intersentia 2006.

13. Joost Vijselaar, 'Isoleren: een historisch dilemma', in: Deviant 2009, nr. 61, p. 16-17. Hij constateert op grond van historische voorbeelden: 'beperking van dwang is nodig en zeker mogelijk, de grootste opgave is echter het consolideren van de cultuur die voor die vermindering noodzakelijk is: toewijding, elan, geduld, persoonlijke aandacht en inzet.' Zie ook zijn belangwekkende boek: Joost Vijselaar, Het gesticht. Enkele reis of retour?. Amsterdam 2010, waarin hij aan de hand van patiëntendossiers het leven binnen instellingen tussen 1890 en 1950 beschrijft. 
kring van (gezondheids)juristen en mensenrechtenactivisten wordt bereikt, is dat een gemiste kans.

Hierbij zou in de tweede plaats kunnen worden gedacht aan het werken met proeftuinen, regio's waarin ggzinstellingen en cliëntenorganisaties het op zich nemen om de werking van het verdrag in het veld actief en inventief te bevorderen en zo best practices te ontwikkelen. De procedure rond dwangopname en dwang'zorg' en met name het zoeken naar minder ingrijpende, maar humanere opvangvormen, zou door beter teamwerk kwalitatief kunnen verbeteren. De kritisch-constructieve inbreng vanuit de rechterlijke macht en vanuit de advocatuur is daarbij onontbeerlijk. ${ }^{14}$

Ten slotte: in de poging het VN-Verdrag meer te laten zijn dan een papieren tijger, moet in de sector van de geestelijke gezondheidszorg worden aangesloten bij langer lopende vernieuwingslijnen. De verdere vermaatschappelijking in de ggz, het accent op rehabilitatie en herstel en het tamelijk succesvolle project om dwang en drang tijdens de opname terug te dringen, ademen dezelfde geest uit als die van het VN-Verdrag. Dat wil bepaald niet zeggen dat dit een simpel karwei is: ook hier zal strijd en volharding nodig zijn om de aspiraties uit het verdrag (gedeeltelijk) te verwezenlijken. De kunst zal zijn het elan aan te wakkeren en in stand te houden. Dat kan bijvoorbeeld door in overlegvormen als moreel beraad na te gaan waar en wanneer de verschillende belangen schuren en te zoeken naar een ethisch te verantwoorden keuze die zo goed mogelijk de persoon, de rechten en de behoefte aan zorg van de patiënt eerbiedigt. Iedereen die de intramurale psychiatrie van nabij kent, weet dat dit weerbarstig, soms teleurstellend maar soms ook heel mooi werk inhoudt. Zowel voor de gebruikers (patiënten, cliënten) als voor de werkers in de geestelijke gezondheidszorg kan het $\mathrm{VN}-$ Verdrag een steun in de rug en een inspiratiebron zijn, maar vanzelf zal dit niet gaan. Er is veel en taai merk nodig om de mensenrechtelijke principes en pretenties in praktijk(en) te vertalen. 